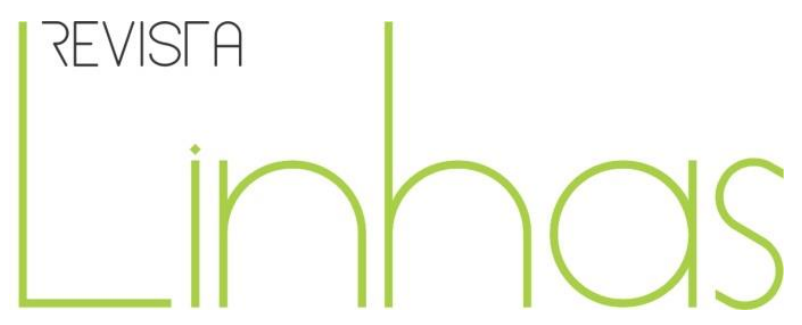

\title{
As implicações da Educação a Distância na formação docente: outros modos de aprender e ensinar
}

\section{Resumo}

O presente artigo traz algumas discussões acerca da educação a distância na formação docente, focando mais especificamente as metodologias utilizadas que trazem implicações para o aprender e o ensinar de professores/as, tutores/as e alunos/as. Trata-se de um relato de experiência vivenciado em um curso de Especialização Lato Sensu em Psicologia da Educação realizado no Núcleo de Tecnologias para a Educação (UEMANET) da Universidade Estadual do Maranhão (UEMA). É uma pesquisa de abordagem qualitativa, primando pela narrativa (auto)biográfica, em que foram utilizados como dispositivos metodológicos: diário de pesquisa, observações e atividades produzidas no Ambiente Virtual de Aprendizagem (AVA). Apresenta como objetivos: refletir acerca das contribuições da Educação a Distância (EaD) no processo de formação continuada de professores/as, bem como compreender as implicações dos dispositivos e artefatos tecnológicos no aprender e ensinar de docentes em formação. Nesse sentido, questiono enquanto problema de pesquisa: Como as tecnologias da informação e comunicação podem contribuir no processo de formação continuada de professores/as mediadas pelo Ambiente Virtual de Aprendizagem? A conclusão a que chegou este estudo foi a de que a utilização de alguns artefatos tecnológicos, disponibilizados no AVA despertam outras habilidades de aprendizagem necessárias nessa sociedade informatizada e globalizada, além do mais, as mudanças geradas em contextos de aprendizagem e ensino, demandam novas dinâmicas e necessidades criadas no bojo do capitalismo e que traz profundas implicações na constituição da docência enquanto formação e desenvolvimento profissional.

Palavras-chave: Professores - Formação. Ensino a distância. Aprendizagem. Inovações educacionais.
Joelson de Sousa Morais

Universidade Estadual de Campinas

- UNICAMP - Campinas/SP - Brasil joelsonmorais@hotmail.com

\section{Para citar este artigo:}

MORAIS, Joelson de Sousa. As implicações da Educação a Distância na formação docente: outros modos de aprender e ensinar. Revista Linhas. Florianópolis, v. 21, n. 45, p. 322-340, jan./abr. 2020. 


\title{
The implications of Distance Education in teaching training: other ways to learn and teach
}

\begin{abstract}
This article brings some discussions about distance education in teacher education, focusing more specifically on the methodologies used that have implications for the learning and teaching of teachers, tutors and students. This is an experience report of a Lato Sensu Specialization Course in Educational Psychology held at the Education Technologies Center (UEMANET) of the State University of Maranhão (UEMA). It is a research of qualitative approach, striving for the (auto) biographical narrative, which were used as methodological devices: research diary, observations and activities produced in the Virtual Learning Environment (VLE). It aims to: reflect on the contributions of Distance Education (DE) in the process of continuing education of teachers, as well as understand the implications of technological devices and artifacts in the learning and teaching of teachers in training. In this sense, it asks as a research problem: How can information and communication technologies contribute to the process of continuing education of teachers mediated by the Virtual Learning Environment? The conclusion reached by this study was that the use of some technological artifacts available in VLE awaken other learning skills needed in this computerized and globalized society. Moreover, the changes generated in learning and teaching contexts demand new dynamics and needs created in the mids of capitalism and that has profound implications for the constitution of teaching as training and professional development.
\end{abstract}

Keywords: Teachers - Training. Distance learning. Learning. Educational innovations. 
O presente texto se inscreve como um relato de experiência, que tem como objetivos: refletir acerca das contribuições da Educação a Distância (EaD) no processo de formação continuada de professores/as, bem como compreender as implicações dos dispositivos e artefatos tecnológicos no aprender e ensinar de docentes em formação.

As discussões aqui realizadas é fruto de minha experiência ocorrida durante o curso de Especialização Lato Sensu em Psicologia da Educação do Núcleo de Tecnologias para Educação (UEMANET) da Universidade Estadual do Maranhão (UEMA), na qual cursei a modalidade de Educação a Distância no período de 2014 a 2016.

Neste texto, tenho a intenção de trazer algumas reflexões me pautando na literatura vigente a respeito do assunto aqui proposto, me reportando a algumas contribuições de autores nacionais e estrangeiros, como Kenski (2003), Coll e Martí (2004), Hancock (2005), entre outros, articulando-os com as experiências por mim desenvolvidas no cotidiano da formação continuada no referido curso.

O mundo vem passando cada vez mais por mudanças vertiginosas que afetam vários setores da sociedade, alterando, inclusive as profissões e o modus operandi dos indivíduos em se tratando do desenvolvimento profissional docente. E nesse contexto, os modos de aprender e de ensinar passaram a ter novas configurações, principalmente, porque a sociedade se configura numa nova era: a da informação e comunicação, que vem alterando significativamente o modo como se aprende e se ensina.

Devido às constantes e profundas mudanças que vêm acontecendo em todas as sociedades, e que são potencializadas pelas tecnologias que vão impactando e trazendo novos saberes e práticas, para várias áreas do conhecimento e da vida, a formação de professores no contexto da Educação a Distância (EaD), vem se adaptando as exigências da sociedade e se utilizando também dos recursos e artefatos tecnológicos para se consolidar. Assim, é preciso que exista estratégias compatíveis e adequadas com esse tipo de educação, relacionadas aos sujeitos pelos quais são ofertados nos cursos em suas diferentes dimensões.

Chartier (2002) traz uma contundente análise acerca dos novos modos de ler e escrever na sociedade contemporânea. O autor designa por "mutação epistemológica”, 
em que alterou significativamente os artefatos de leitura e escrita, trazidas pela globalização. Segundo o autor: “[...] a revolução da textualidade digital constitui também uma mutação epistemológica que transforma as modalidades de construção e crédito dos discursos do saber." (CHARTIER, 2002, p. 25). Dessa forma, os processos de aprendizagem no contexto da escolarização, quando pautados por uma racionalidade que leve em consideração os saberes e fazeres tecnológicos, podem representar um contexto privilegiado de formação, aprendizagem e desenvolvimento profissional de modo significativo para os/as professores/as, e consequentemente, os alunos.

A sociedade da informação, na qual estou vivendo e experienciando atualmente, configura-se por processos constantes e mutáveis na construção do conhecimento. Nesse sentido, cada vez mais vão se ampliando em todos os contextos e cenários, a acessibilidade a aparatos tecnológicos que vão impactando na vida social, econômica e cultural dos sujeitos, formando novas identidades (HANCOCK, 2005), e novas formas de pensamento e ação (KESNKI, 2003), trazidas pela Revolução Industrial, que teve forte impulso no surgimento dos novos artefatos de cunho tecnológico em todo o mundo.

Diante do exposto, apresento como questão de partida: Como as tecnologias da informação e comunicação podem contribuir no processo de formação continuada de professores/as mediadas pelo Ambiente Virtual de Aprendizagem?

Já que a Educação a Distância é uma modalidade de ensino que possibilita a formação dos sujeitos através da produção e não somente da reprodução do conhecimento, entendo que essa forma de ensino tem propiciado inúmeros processos de apropriação de diversos dispositivos tecnológicos e modos de ensinar e aprender, mas que, precisam ser promovidos de uma forma mais eficaz, consubstanciando-se em verdadeiras e profícuas aprendizagens por quem as utiliza, tanto do ponto de vista dos professores nos cursos ofertados na $\mathrm{EaD}$, quanto do ponto de vista dos alunos que têm inúmeros desafios e possibilidades de vivenciarem esse processo de ensino e aprendizagem, construindo as habilidades necessárias para tal.

Nesse sentido vale ressaltar que: 
O texto eletrônico, tal qual o conhecemos, é um texto móvel, maleável, aberto. O leitor pode intervir em seu próprio conteúdo e não somente nos espaços deixados em branco pela composição tipográfica. Pode deslocar, recortar, estender, recompor as unidades textuais das quais se apodera. (CHARTIER, 2002, p. 25)

É diante dessa flexibilidade que posso construir novos saberes e fazeres por meio dos cursos ofertados na modalidade EaD. Pois, apesar haver diretrizes para que seja realizado, existe também a possibilidade de ser desenvolvido, conforme a criatividade dos cursistas, dando uma certa autonomia durante a realização dos cursos que se encaixam nesse perfil. Além do mais, existem inúmeras possibilidades propiciadas pelas atividades que são apresentadas nas plataformas ofertadas pelos cursos que não são fixas, podem ser maleáveis, desde que o sujeito participe ativamente do processo de construção do conhecimento, necessário às suas aprendizagens.

É sobre essas questões que vou me debruçar nas linhas que se seguem, não querendo responder em sua totalidade aos questionamentos e ideias aqui propostos, mas trazendo reflexões instigantes para pensar as implicações da Educação a Distância na formação continuada de professores, os quais são oriundos de diversas formações no âmbito das licenciaturas. Uma vez que cada dia que passa, mais as práticas educativas e formativas estão sendo ofertadas na modalidade de Educação a Distância. Trata-se, portanto, de um novo paradigma sob o qual não posso ficar aquém, pois aprendo de diferentes formas e com maiores possibilidades acessíveis de construção do conhecimento científico.

\section{Os dispositivos metodológicos da pesquisa narrativa (auto)biográfica}

A presente pesquisa é de abordagem qualitativa, primando, especificamente pela perspectiva da narrativa (auto)biográfica em educação, uma vez que trouxe os meus próprios percursos dos itinerários formativos, os quais trilhei ao longo do curso de Especialização Lato sensu em Psicologia da Educação, ofertado pelo NEAD/UEMA, que ocorreu entre os anos de 2014 e 2016, por meio da plataforma online de acesso e participação nas disciplinas, contendo videoaulas, fóruns, chats e outros dispositivos 
oferecidos no sistema AVA, produzidos pelos/as professores/as do curso, e intermediado pelos/as tutores.

Assim, cabe salientar que "[...] a pesquisa narrativa começa, caracteristicamente, com a narrativa do pesquisador orientada autobiograficamente, associada ao puzzle (enigma) da pesquisa, denominado, por alguns, como problema de pesquisa ou questão de pesquisa." (CLANDININ; CONNELLY, 2015, p. 74).

Enquanto dispositivos metodológicos, utilizei um entrelaçamento entre: 1) observações; 2) diário de pesquisa; e 3) as produções e atividades desenvolvidas no AVA durante a realização do curso.

As observações foram por mim tomadas ao longo dos encontros semipresenciais no polo da Universidade Aberta do Brasil (UAB), vinculada à UEMA, e localizada no campus da Cidade de Caxias - MA, localizada numa escola da rede pública de ensino, na qual os encontros se realizaram, bem como, por meio das atividades e interações que ocorreram mediadas pelos diferentes artefatos e meios de comunicação que foram sendo propiciados na plataforma online e nos grupos das redes sociais criados especificamente para atender as demandas e necessidades do curso.

Em relação ao diário de pesquisa, foi um outro dispositivo produzido nesse contexto, e que venho utilizando também em minhas pesquisas e produção do conhecimento científico, tanto do ponto de vista de uso como dispositivo de ensino, quanto como de pesquisa e reflexão de minha própria prática e formação, na qual registro as minhas narrativas escritas ao longo do que vivi e experienciei.

Diante do exposto, convém elucidar que:

A narrativa escrita constitui um suporte particularmente adequado para a pesquisa dos processos de formação e de conhecimento, porque dá acesso tanto às partes que a compõem como a um conjunto a que foi atribuído um título. Além disso, porque contém simultaneamente o fatual e o pré-interpretado. (JOSSO, 2010, p. 215)

Dessa forma, os registros escritos narrativamente, me permitem materializar o meu pensamento, frutos dos percursos trilhados no campo da formação e da experiência pessoal e profissional, dando possibilidades de reflexão e levando-me a uma tomada de 
consciência do processo, enquanto elemento disparador de tomar forma, de propiciar uma transformação plausível e fundamental e que ganha legitimidade pela narrativa que produzo no diário.

\section{Novas práticas das Tecnologias da Informação e Comunicação (TICs) para um novo contexto na EaD}

O processo de industrialização que foi se ampliando consideravelmente em todo o mundo, trouxe consigo profundas e significativas mudanças na conjuntura social, de tal forma que não se pensa e não se faz mais as mesmas coisas como antes. Isso porque as dificuldades que o sujeito enfrentava no passado, decorrentes de práticas manuais e que demandavam um maior tempo e resultavam em lentidão, como mostram Catapan et al (2008), hoje já não existem mais, tendo em vista as facilidades que as tecnologias têm propiciado através de seus inúmeros dispositivos e artefatos.

Com relação à EaD, vejo que, embora tenha adotado inúmeras possibilidades para a formação de novas mentalidades no seu cotidiano, esta tem ficado muito mais a cargo de quem se beneficia da modalidade, ou seja, dos sujeitos que a buscam como mecanismo de formação, seja ela inicial ou continuada. Assim, é preciso criar uma cultura de independência e autonomia, para cumprir prazos, desenvolver habilidades com os recursos disponíveis, através dos softwares, bem como construir uma "autogestão da aprendizagem" para se concretizar aprendizagens essenciais na EaD (CATAPAN et al., 2008; TORRES SANTOMÉ, 2013).

Dentre as contribuições que essa modalidade de ensino tem propiciado, posso destacar que: a própria formação dos sujeitos tem sido muito fortalecida com a presença dessas tecnologias, uma vez que muitos ainda não podem fazê-lo presencialmente; as próprias políticas públicas têm construído alguns aspectos norteadores, embora seja preciso ampliá-los consideravelmente, sobretudo, no cenário brasileiro; e as pessoas estão cada vez mais aprendendo numa maior proporção fora da escola e das instituições de ensino, do que dentro delas, devido às constantes interações com inúmeros artefatos da tecnologia com os quais se estabelecem e buscam, entre tantas outras séries de fatores potenciais que esta modalidade tem trazido. Dessa forma “[...] Nem sempre o caminho proposto pela equipe é o desenvolvido pelos estudantes. O movimento didático 
e o movimento da aprendizagem podem se diferenciar, pois se dão em tempos e espaços

diferentes." (CATAPAN et al, 2008, p. 76), e cada pessoa apresenta um ritmo diferente, tempos necessários, etapas a serem alcançadas/atingidas e encara os resultados também de formas variadas. O mais importante é que acabam construindo suas próprias possibilidades de aprendizagem.

Não posso, contudo, deixar de compreender que as TICs vieram para melhorar o processo de ensino e aprendizagem no que se refere à Educação a Distância, e que muito das suas potencialidades e contribuições não tem sido exploradas ainda, em detrimento de algumas culturas, como fruto das compreensões e usos das tecnologias e também em decorrência de aspectos econômicos de populações que não tiveram acesso em maior proporção.

Entendo, então que:

No âmbito da educação, as novas tecnologias favorecem novas formas de apresentar, organizar, comunicar, aprender e obter informações; bem como de se relacionar e trabalhar com outros companheiros, sejam eles estudantes, professores ou qualquer outra classe de profissionais. (TORRES SANTOMÉ, 2013, p. 21)

A reflexão acima, me leva a entender que existem grandes e inúmeras possibilidades de se trabalhar no contexto do processo de ensino e aprendizagem, as quais devem ser galgadas por novos contextos pelos professores, tutores, e cursistas da EaD, em suas respectivas práticas cotidianas de formação. Mas como fazer isso? Quais os dispositivos metodológicos e processos de produzir conhecimento potencialmente significativos para se trabalhar com as TICs no contexto da Educação a Distância?

Primeiramente, alerto, enquanto professor formador de professores, pesquisador e como quem já vivenciou essa experiência de educação a distância, que meus alunos de hoje estão chegando às salas de aula com um cabedal mais amplo de conhecimentos e em muitos aspectos, mais plurais e híbridos. Isso exige cada vez mais uma dinamicidade dos processos educativos, em função das novas demandas e necessidades que me são apresentadas, inclusive, do perfil de aluno que se apresenta, me fazendo criar outros tantos dispositivos metodológicos, e suscitar reflexões pertinentes e atuais, que possam contribuir em sua formação, uma vez que muitos/as são sujeitos que estão em cursos de 
licenciaturas ou que estão diretamente ligados à área da educação e da formação pedagógica para a docência.

Nesse sentido, preciso ficar atento às mudanças na sociedade, pois a escola, como instituição social, será campo de desenvolvimento profissional de meus alunos que, como futuros professores/as, irão se defrontar com uma realidade multifacetada, na educação de inúmeras crianças que por eles passarão, uma vez que "[...] as crianças que ocupam os bancos escolares são as mesmas que assistem televisão e vídeo em casa." (HANCOCK, 2005, p. 235). Esse contato com o mundo externo e tecnológico tem contribuído para a formação de novas identidades culturais, como esse mesmo autor vem apontando, em que as crianças vivenciam e levam para a escola.

Uma crítica contundente que assevera essa discussão sobre a formação de professores diante das novas demandas apresentadas no cotidiano da prática escolar, é a tecida por Imbernón, ao assinalar que:

A escola, tal como a conhecemos, criada na modernidade do século XVIII, consolidada em suas funções de educação da cidadania no século XIX e renovada pelos movimentos da escola nova durante o século $\mathrm{XX}$, tenta educar crianças do século XXI com professores formados em procedimentos educacionais do século XX. (IMBERNÓN, 2016, p. 87)

Penso que, mediante o exposto acima, com igual dimensão para a Educação à Distância, se o sujeito não buscar se envolver, se desdobrar e criar hábitos de estudo, pesquisa, articulação e discussão de ideias, conhecimentos com seus pares, os professores e tutores, enfim, criar uma cultura de participação ativa e exploração do ambiente virtual de aprendizagem em suas múltiplas dimensões, tampouco poderá avançar em habilidades e construção de saberes, fundamentais ao sucesso que se pretende construir nesta modalidade de ensino.

No âmbito dos processos psicológicos, a partir de uma perspectiva construtivista, evidenciada por autores espanhóis, como Coll e Martí (2004), estes apresentam algumas características principais das Novas Tecnologias da Informação e Comunicação (NTIC), relevantes para os processos de ensino e aprendizagem, as quais cada uma tem uma característica específica, e atende a significações diferenciadas, de acordo com quem as 
desenvolve, e que isso me ajuda a pensar como se processa no contexto da EaD, a saber: Formalismo, Interatividade, Dinamismo, Multimídia e Hipermídia. A ideia apresentada pelos autores, é que estas características sejam utilizadas no cotidiano da prática docente, no sentido de promover profícuas e produtivas aprendizagens, possibilitando, assim a construção do conhecimento, embora isso seja uma realidade pouca vivenciada, de fato, no dia a dia das pessoas.

As características apontadas acima são consideradas ainda por Coll e Marti (2004), como potentes mediadores do funcionamento psicológico das pessoas que as utilizam. Por isso, a adequação a Educação à Distância, considero ser importante para se destacar essas características articulando-as às singularidades dos sujeitos na produção do conhecimento, desenvolvendo, inclusive, habilidades essenciais à convivência humana, nos dias atuais, em que enfrento em todos os espaços e contextos em relação ao contato e a vivência com as TIC's, desde a minha casa, como no meu trabalho, na formação acadêmica, e no contato com outras pessoas e em lugares diversos que a sociedade me apresenta.

Percebo que essas características não se desenvolvem apenas em um plano utópico e de difícil concretização. Para isso, os próprios tutores e professores podem se valer do que possuem para trabalhar outros dispositivos metodológicos, que despertem o próprio interesse seja dos alunos da EaD, como de si próprios, configurando-se, inclusive, como uma (auto)formação.

Um exemplo diante do exposto, refere-se a utilização de outros recursos tecnológicos, como tem sido propiciado no Curso de Especialização em Psicologia da Educação pela UEMANET, do qual já comentei neste texto. Esses recursos são correio eletrônico, o whatsApp e o facebook, que tem servido como subsídios para encurtar as distâncias entre professor/a, tutor/a e alunos/as, bem como entre os próprios alunos/as, no sentido de melhorar as compreensões, entendimentos, reflexões e mesmo avisos, convites, dúvidas, informações, os quais chegam com mais rapidez a cada um destes sujeitos.

Embora, essas ferramentas tecnológicas apresentam uma dupla face, em relação a aspectos positivos e negativos (me refiro às redes sociais do WhatsApp, o facebook e o correio eletrônico), neste texto, apresento apenas o modo como as mesmas foram 
utilizadas, especificamente, para atender a um contexto de formação continuada de professores/as durante o referido curso já mencionado, para atender aos propósitos preconizados pelos cursistas e no processo de interação entre tutores, professores/as formadores/as e alunos/as que eram, em sua maioria, educadores ou profissionais licenciados, que estavam realizando o curso.

O uso do WhatsApp, uma ferramenta bem contemporânea, configurando-se como educativa tem tido um maior impacto, porque é uma novidade para as pessoas nesta última década, lançado recentemente há alguns anos, e que tem despertado todo o mundo para o seu uso. No que se refere ao curso já citado, me aproprio rapidamente e me familiarizo com as informações do curso, a troca de experiências realizadas entre os alunos, e de igual modo com os/as professores/as e tutores/as, além de trabalhar as habilidades de reflexão, crítica, dúvida, e apropriação de novos saberes e fazeres, o que acaba extrapolando para uma dimensão mais complexa, até no plano pessoal.

Assim, discutia com os/as demais alguns posicionamentos, ideias, ponto de vista, referências e/ou reflexões de algum autor, reportagem, entrevista, livro, etc., que eram elementos que transitavam entre as atividades do curso, bem como oriundas dos encontros cotidianos que eram propiciados ao longo do curso. São discussões de cunho crítico, reflexivo que me ajudaram a pensar sob outros ângulos que por acaso não tinha pensado e/ou vivido.

Outro aspecto relevante, é que durante as discussões e atividades propiciadas pelos recursos tecnológicos como o do WhatsApp, por exemplo, é que pude concordar ou discordar com o/a colega de turma, ou até mesmo com professores/as e/ou tutores/as, embora, para os primeiros se torna algo ainda não consolidado em termos de acessibilidade, tendo os tutores uma maior aproximação que facilita os processos de aprendizagem e ensino.

É no contexto de utilização do WhatsApp, que percebi como uma ferramenta potencialmente significativa e produtiva para um curso de Educação à Distância, como tem sido com o de Especialização em Psicologia da Educação, por eu cursado. Isso se torna possível, à medida que muitas vezes não tenho tempo o suficiente para ligar um computador, e então olhar o meu e-mail, ou o facebook, e até mesmo a plataforma do Ambiente Virtual de Aprendizagem-AVA moodle da UEMANET, para ver ou me aperceber 
dos prazos, avisos, questões imediatas e importantes que possam me alertar para usar, no momento certo, oportuno e viável o AVA.

Situando as ferramentas apresentadas acima, como o correio eletrônico, o facebook e, sobretudo, o WhatsApp, ainda no contexto aqui discutido acerca da ideias expressas por Coll e Martí (2004), entendo que o formalismo, a interatividade, o dinamismo, a multimídia, e a hipermídia, são elementos que estão acessíveis à maioria das pessoas na sociedade, seja através de um computador, como de um celular, de um vídeo, ou mesmo de um programa de televisão ou internet, as quais podem trabalhar outros conteúdos, outras formas de ensino e aprendizagem, e que requer uma substancial modificação nas práticas vigentes para ter um feedback a altura da realidade que minhas aulas revelam todo o dia diante da sociedade da informação, que está em constante e profundas mudanças, e assim, permitir construir conhecimentos potencialmente significativos.

\section{A emergência de possibilidades metodológicas diante da EaD}

São inúmeras as implicações que as Tecnologias da Informação e Comunicação exercem na vida do sujeito. E no que se refere à Educação à Distância, muitas questões têm impactado o trabalho de professores/as, tutores/as e alunos/as, e que tem repercutido, sobremaneira, nos processos de aprendizagem e ensino, cotidianamente.

Muitas vezes, a formação junto às TIC's não desenvolve todas as habilidades necessárias para se aprender no contexto de ensino e aprendizagem na EaD de uma forma produtiva.

Quando chegam nos Ambientes Virtuais de Aprendizagem (AVA), o docente precisa construir novas possibilidades de ensino, e vai aprendendo a ser professor, com todas as peculiaridades que uma sala virtual de aprendizagem apresenta. $E$ as tecnologias se mostram, como outra faceta do aprender também a manuseá-las (do ponto de vista operacional), e trabalhá-las no contexto de ensino e aprendizagem (do ponto de vista pedagógico e metodológico). Isso também se aplica aos alunos, que muitas vezes nunca tiveram vivenciado um processo de aprendizagem como esse, diferente daquele contato humano, com o qual o sujeito está acostumado a estabelecer, presencialmente. 
Assim, se torna um imperativo entender que:

$\mathrm{Na}$ sociedade em que proliferam as mais diversas tecnologias de informação e comunicação, o conhecimento encontra-se também disponível em imagens, gravuras, fotos, emissões radiofônicas, telas de televisores e computadores. Um conhecimento fragmentário, tão disponível quanto um livro. Um conhecimento sedutor que se apresenta com todos os recursos de sons, cores, imagens e movimentos. Que pode ser acessado e manipulado a qualquer instante, através dos processos interativos de comunicação eletrônica - redes, televisão e jogos, programas multimídia, etc... (KENSKI, 2003, p. 90)

Portanto, as tecnologias não são apenas o uso do computador, como muitos tem reduzido a pensar e a fazer suas aulas, se utilizando dessas maneiras. Na verdade, o computador é um artefato bastante avançado e que oferece inúmeras (mas não a única), possibilidades de ensinar e aprender.

Além do computador, ressalto ainda que existem os celulares, os tablet's, iphones, entre outros artefatos tecnológicos, os quais muitas vezes passam a fazer parte com maior facilidade do cotidiano das pessoas nessa sociedade atual em que estou imerso.

Com essa gigantesca “mutação tecnológica” (HANCOCK, 2005), que estou vivendo cotidianamente, é possível criar inúmeras possibilidades de se trabalhar didática e metodologicamente determinados conteúdos, inclusive, contribuindo para as aulas serem mais agradáveis, atrativas e motivadoras para tutores/as, professores/as e os/as alunos/as nesta modalidade de ensino. Sobretudo, se for levado em consideração as inúmeras fontes e artefatos que são dispostos no contexto da educação e da sociedade. E nesse processo de interação posso me valer da criatividade, autonomia e disposição para buscar outros tantos recursos e possibilidades de envolver e despertar os/as alunos/as e os/as professores/as, seja os/as alunos/as com eles/as próprios/as, como destes/as para com os/as professores/as e vice-versa.

Então, como conectar metodologia com tecnologia na Educação a Distância?

Não significa dizer que, pelo fato de as salas virtuais de aprendizagem possuírem os programas e instruções necessárias para desenvolvê-las, é que as aulas serão sempre melhores e diferentes. Isso não tem absolutamente nada a ver. A questão é para, além 
disso, ou seja, por mais que existam as ferramentas essenciais na EaD para o ensino com as TIC's, é preciso articular a realidade de mundo dos educandos, valorizando sua linguagem, seus modos diferentes e heterogêneos de aprender, com o que os/as professores/as disponibilizam e sabem também ensinar, porque uma coisa é ter a ferramenta e saber ensinar, a outra é mesmo assim tê-la e não saber desenvolver os procedimentos necessários no processo de ensino e aprendizagem.

Além do mais, muitas vezes, os/as professores/as e tutores/as até se esforçam para apresentarem os diversos dispositivos e conhecimentos tecnológicos, mas os/as alunos/as, muitas vezes não dão a devida importância, devido ao fato tanto de não ter conhecimento com essa nova realidade (no sentido de saber manuseá-la, operacioná-la e explorar ambientes no contexto da navegação online), bem como não ter tido vivências e formação para utilizá-las, assim como a operacionalização do tempo e dos prazos que caminham vertiginosamente, sem que o sujeito possa se aperceber do tempo, e o deixa, muitas vezes a fazer e a cumprir qualquer atividade sempre para o último caso ou já expirando o tempo, o que isso não deve acontecer, e nem é salutar. Portanto, não é possível alfabetizar tecnologicamente, quando sua própria cultura está aquém das TIC's. Embora eu não queira aqui generalizar, pois possuem algumas exceções nesse processo, como em todo o caso.

Kenski (2003, p. 90) elucida a necessidade de entendimento de que estou diante de "[...] novas escolas, novas memórias. Novas tecnologias, novas metodologias", e é uma construção que deve ser paulatinamente tecida por todos/as os/as professores/as, tutores/as e alunos/as em seus respectivos cotidianos. Mesmo que não tenham tido a formação ideal e necessária para tal, podem buscar romper com os paradigmas ultrapassados e hegemônicos de formação e integrar as TIC's no cotidiano da EaD, utilizando os inúmeros dispositivos metodológicos e artefatos que existem ao alcance, mas de uma forma positiva, inclusive trabalhando vários conteúdos, a exemplo da interdisciplinaridade, em busca do exercício e do direito a uma democracia cognitiva e informacional, como propõe Edgar Morin (2013).

Entendo ainda, que urge uma ressignificação do processo de formação de professores/as na EaD para atuar junto às TIC's aonde quer que esteja ou passe a se desenvolver profissionalmente. E para isso, não posso deixar de ressaltar as importantes 
contribuições acerca deste debate emergente e fundamental, mostrando que uma das propostas é que "[...] a formação de professores seja de fato enriquecida pela recontextualização das TIC, sem se esgotar na racionalidade instrumental, para que a alardeada ‘democratização’ possa vir a prescindir das aspas.” (BARRETO, 2013, p. 149).

Uma das possibilidades de ressignificar o uso das TIC's no contexto de formação continuada de professores/as, é utilizar as ferramentas que possam ter acesso aos cursistas de modo mais fácil, rápido e que se torna uma via de produção de significados para aprender e ensinar cotidianamente. Aspectos estes que citei através da utilização, além do AVA, do facebook, correio eletrônico e whatsapp, entre outros que puder ser útil, e estiver compatível com o contexto de ensino e aprendizagem, tendo também como representativo nessa interação, a criatividade e autonomia de professores/as, tutores/as e alunos/as.

Para isso, enfatizo que um desafio a ser construído e superado, para a conexão entre metodologia e tecnologia na EAD seria:

[...] conhecer a si mesmo, conhecer suas próprias (antigas e novas) potencialidades e particularidades. Um movimento contínuo para formarse através da comunicação permanente com os mais diversos elementos da natureza. Este é o grande desafio para as novas escolas, novas metodologias, novos mestres. (KENSKI, 2003, p. 92)

Trata-se, assim, de uma percepção que muitas vezes o sujeito não chega a visibilizar em seus cotidianos, ficando presos às práticas rotineiras e repetitivas. Resta, portanto, um olhar mais holístico, abrangente, complexo e ao mesmo tempo singular diante do que cada um pensa e faz, e com quem lida diariamente, isto é, com quem o/a docente educa, ensina e aprende faz toda uma diferença a maneira como é percebido estes sujeitos em relação ao que é selecionado, priorizado e feito no cotidiano da atuação profissional, enquanto professores/as. Só faz sentido e traz produtividade, uma educação a distância em que os sujeitos buscam mobilizar os saberes e a efetividade das práticas tecidas cotidianamente em processos de colaboração permanente. 


\section{Considerações finais}

Em suma, compreendo que diante de todos os acontecimentos diários que alunos/as, professores/as, tutores/as e demais sujeitos enfrentam em inúmeros espaços, no contato com várias ferramentas e artefatos tecnológicos, faz-se mister ressignificar os saberes e fazeres mobilizados por estes/as, para construir uma Educação à Distância a altura da sociedade que se apresenta, uma vez que as informações circulam de modo muito rápidas, e é necessário transformá-las em conhecimento produtivo e essencial para a compreensão e entendimento do sujeito no mundo sobre a realidade e para avançar para outros saberes que exigem de cada um/a um nível maior de reflexão, criticidade e construção desses saberes.

Um dos grandes desafios da EaD é a adoção de saberes e práticas que sejam compatíveis com o nível da educação que está sendo ofertada, bem como dos dispositivos que possam ser utilizados no cotidiano da formação dos sujeitos, para facilitar a produção do conhecimento e o próprio desenvolvimento do curso, que seja pautado pela qualidade da formação. Uma formação significativa e que atenda às necessidades atuais e contemporâneas do curso que está sendo desenvolvido.

Apesar de ainda existir algumas lacunas, no que diz respeito ao cumprimento dos prazos, do desenvolvimento das habilidade de operacionalização dos programas e ferramentas disponíveis no AVA, e na produção do próprio conhecimento permeado pelas atividades das disciplinas, entendo que são por meio dessas limitações que a EaD tem conseguido suprir suas carências, e ter avançado em termos de construção de novos saberes e práticas para serem viabilizados nos vários processos de aprender e ensinar nesta modalidade de educação.

Pode ser que as ideias e sugestões aqui apresentadas, não tenham se configurado como algo novo e irreverente, mas, pode servir como subsídios para novas reflexões, e mesmo a adoção de práticas e saberes para os cursos de EaD, aos profissionais que trabalham nesta área, e mesmo professores/as, alunos/as, tutores/as e pesquisadores/as interessados na temática.

Considero, em síntese, que os instrumentos e artefatos tecnológicos, sobretudo, os aqui citados representam outras possibilidades de educação e ensino, e que muitas 
vezes podem não estar sendo percebidos pelos profissionais e cursistas que estão engajados e mesmo fazendo parte do cotidiano da Educação à Distância, onde quer que estejam.

Os dispositivos metodológicos, portanto, fazem um diferencial em um curso de formação continuada de professores/as na educação à distância, sobretudo, porque dão condições de compreender os saberes e fazeres que permearão as suas práticas pedagógicas cotidianas em múltiplas realidades cotidianas em que os sujeitos se defrontarão profissionalmente.

É possível ainda refletir, enquanto resultados que esta pesquisa propiciou, que a utilização de alguns artefatos tecnológicos, disponibilizados no AVA despertam outras habilidades de aprendizagem necessárias nessa sociedade informatizada e globalizada, além do mais, as mudanças geradas em contextos de aprendizagem e ensino, demandam novas dinâmicas e necessidades criadas no bojo do capitalismo e que traz profundas implicações na constituição da docência enquanto formação e desenvolvimento profissional.

A tomada de iniciativa no que preze pela qualidade da formação, e mesmo de processos de (auto)formação podem representar possibilidades outras de potencializar o cotidiano da prática docente em processos de desenvolvimento profissional. E eis, portanto, uma possibilidade que está esperando cada sujeito empreender, em busca da emancipação social, na construção de um mundo melhor, mais democrático e em profunda conexão, reflexão e construção do conhecimento mediadas pelo mundo tecnológico.

Portanto, a esperança de construção de um mundo melhor, com mais informações, conhecimentos e produção de sentidos nas práticas humanas, formativas e educacionais podem ser suscitados por práticas, reflexões e saberes construídos e mobilizados em vários contextos de vida e profissão e que são entrelaçados na vida, pesquisa-formação e prática profissional dos sujeitos. 


\section{Referências}

BARRETO, Raquel Goulart. Formação de professores a distância: políticas e práticas. In: GATTI, B. et al. (orgs.). Por uma política nacional de formação de professores. São Paulo: Editora Unesp, 2013.

CATAPAN, Araci Hack et al. Introdução à educação a distância. Florianópolis: Filosofia/EAD/UFSC, 2008.

CHARTIER, Roger. Os desafios da escrita. Tradução de Fulvia M. L. Moretto. São Paulo: Editora UNESP, 2002.

CLANDININ, D. Jean; CONNELLY, F. Michael. Pesquisa narrativa: experiências e histórias na pesquisa qualitativa. Tradução: Grupo de Pesquisa Narrativa e Educação de Professores ILEEL/UFU. 2.ed. rev. Uberlândia: EDUFU, 2015.

COLL, César; MARTí, Eduardo. A educação escolar diante das novas tecnologias da informação e da comunicação. In: COLL, César; MARCHESI, Álvaro; PALACIOS, Jesús (orgs.). Desenvolvimento psicológico e educação. Tradução Fátima Murad. 2. ed. Porto Alegre: Artmed, 2004.

HANCOCK, Alan. A educação e as novas tecnologias da informação e da comunicação. In: DELORS, Jacques (org.). A educação para o século XXI: questões e perspectivas. Trad. Fátima Murad. Porto Alegre: Artmed, 2005.

IMBERNÓN, Francisco. Qualidade do ensino e formação do professorado: uma mudança necessária. Tradução Silvana Cobucci Leite. São Paulo: Cortez, 2016.

JOSSO, Marie-Christine. Experiências de vida e formação. Tradução de José Cláudio, Júlia Ferreira; revisão Maria da Conceição Passeggi, Marie-Christine Josso. 2. ed. rev. ampl. Natal, RN: EDUFRN; São Paulo: Paulus, 2010.

KENSKI, Vani Moreira. Memórias e formação de professores: interfaces com as novas tecnologias de comunicação. In: CATANI, D. B. et al (orgs.). Docência, memória e gênero: estudos sobre formação. 4. ed. São Paulo: Escrituras Editora, 2003.

MORIN, Edgar. A via para o futuro da humanidade. Tradução de Edgar de Assis Carvalho, Mariza Perassi Bosco. Rio de Janeiro: Bertrand Brasil, 2013.

TORRES SANTOMÉ, Jurjo. Currículo escolar e justiça social: o cavalo de Troia da educação. Tradução: Alexandre Salvaterra; revisão técnica: Álvaro Hypolito. Porto Alegre: Penso, 2013. 
Recebido em: 13/12/2018 Revisões requeridas: 13/03/2019 Aprovado em: 06/12/2019

Universidade do Estado de Santa Catarina - UDESC Programa de Pós-Graduação em Educação - PPGE Revista Linhas Volume 21 - Número 45 - Ano 2020 revistalinhas@gmail.com 